This article has been published in a revised form in Social Philosophy and Polics https://doi.org/10.1017/S0265052516000224 This version is free to view and download for private research and study only. Not for redistribution, re-sale or use in derivative works. (C) 2016 Social Philosophy \& Policy Foundation 


\section{Idealization, Justice, and the Form of Practical Reason*}

Simon Hope, Philosophy, University of Stirling

In this paper I argue for three claims. First, the question of which, if any, idealizations are justifiable in philosophical reflection on morality and justice cannot be separated from the question of what the appropriate form of reflection is. My second claim, invoking the ancient distinction between the forms of practical and theoretical reason, is that the appropriate form of reflection on standards of justice and morality is practical rather than theoretical. My third claim is that the form of practical reason cannot support many of the idealizations typically deployed in modern moral and political philosophy.

In $\S 1$, I give two reasons why debates over ideal and non-ideal theories of justice and morality must encompass debate over the appropriate form of reflection. Constraints on the form reflection must take may be idealized away, and I illustrate the point with a discussion of Liam Murphy's 'non-ideal' account of beneficence. Secondly, assumptions about the appropriate form of reflection shape one's position on the acceptability of idealization. By way of illustration I consider some recent objections to the distinction between idealization and abstraction. \$2 then introduces the distinction between the forms of practical and theoretical reason. Finally, in $\S 3$, I argue that, of these two possible forms, reflection on standards of justice and morality should have the form of practical reason. I then argue that this conclusion constrains the use of idealization in reflection on standards of morality and justice. Practical reason cannot idealize away the conditions that make such reasoning shareable and action-guiding.

\section{A lacuna in the current ideal/non-ideal debate(s)}

In the last decade or so debate has blossomed concerning philosophical reflection on justice, a debate often portrayed as between proponents of "ideal theory" and "non-

\footnotetext{
* Grateful thanks to: Rowan Cruft, Katrin Flikschuh, Adrian Haddock, Brian Ho, Rob Jubb, Sem de Maagt, Onora O’Neill, David Schmidtz, my Stirling colleagues, and incredibly helpful audiences at UCL, Arizona, and Auckland.
} 
ideal theory". ${ }^{1}$ Yet the suggestion of only two camps seems a little misleading, as it would for any complex philosophical issue. Defenders of "ideal theory" disagree about the extent to which to idealization can be used, ${ }^{2}$ while critics of idealization do not offer mutually complementary objections to it: ${ }^{3}$ debates continue on numerous fronts with only partial overlap. If there is a question that links the varied debates subsumed under the heading of "ideal vs non-ideal theory", it is this: "Which idealizations are philosophically justifiable and which are not?" This question is most commonly asked of philosophical reflection concerning justice. But it might be asked of any ethical concept and, while I focus primarily on justice, I intend to make a general point about reflection involving ethical concepts, of which justice is just one.

The debates around ideal theory and idealization are typically shaped by an assumption that risks foreshortening the scope of the question that appears to link them. All instances of idealization falsify features of the world. As Onora O'Neill notes, '[a]n assumption, and derivatively a theory, idealizes when it ascribes predicates - often seen as enhanced, 'ideal' predicates - that are false of the case in hand, and so denies predicates that are true in that case. ${ }^{4}$ Debates over idealization with respect to justice typically consider a restricted set of features of the world that could be idealized away. Debates centre on whether theorizing should idealize away the circumstances of politics, or historic injustice, or limited scarcity, or noncompliance, or various constraints on feasibility, to give just some examples. What this set of features has in common is that they are all features of the world as it is

\footnotetext{
${ }^{1}$ This terminology is popularly taken from John Rawls, A Theory of Justice (rev. ed. Oxford: Oxford University Press, 1999), 8. Debates around the issue are actually a lot older: compare Michael Oakeshott, Rationalism in Politics and Other Essays (Indianapolis: Liberty Fund, 1962).

${ }^{2}$ Contrast, for example, A. John Simmons, "Ideal and Nonideal Theory", Philosophy and Public Affairs 38, no.1 (2010): 5-36; Laura Valentini, "On the Apparent Paradox of Ideal Theory", The Journal of Political Philosophy 17, no.3 (2009): 332-355; David Estlund, "Utopophobia", Philosophy and Public Affairs 42, no.2 (2014): 113134; and Gerry Cohen, Rescuing Justice and Equality (Cambridge MA: Harvard University Press, 2008).

${ }^{3}$ Compare, for example, the very different criticisms offered by Amartya Sen, The Idea of Justice (Cambridge MA: Harvard University Press, 2009); Charles W. Mills, "Ideal Theory as Ideology", Hypatia 20, no.3 (2005): 165-184; Lorna Finlayson, The Political is Political (London: Rowman and Littlefield, 2015); and Lea Ypi, Global Justice and Avant-Garde Political Agency (Oxford: Oxford University Press, 2011). ${ }^{4}$ Onora O'Neill, Towards Justice and Virtue (Cambridge: Cambridge University Press, 1996), 41.
} 
understood independent of theory: they are features of the world in which the proposals of theory are to be instantiated. ${ }^{5}$

I do not wish to suggest that debating these idealizations is misguided. ${ }^{6}$ My suggestion is that there are at least two good reasons to think crucial issues are missed if idealizations of this sort were all we considered. We would miss the possibility that reflection itself can be idealized, and we would miss the way in which assumptions about the form of reflection shape existing debates.

\section{1: Idealizing away constraints on reflection}

The examples of controversial idealization just given all concern features of the world that relate to the task of instantiating the conclusions of some piece of moral or political philosophy. Yet the philosophy itself is also part of the world - it is a construction of thought, constructed out of a particular intellectual inheritance, constructed by a thinker with finite powers of cognition and reflection. No contributors to current debates would deny this, yet the point receives surprisingly little attention. ${ }^{7}$ This is unfortunate, as capacities for reflection, and the form reflection takes, are also aspects of the world, and theorizing may idealize both.

To help vindicate this thought, and to make it less obscure, I would like to briefly illustrate how it applies to a position claiming the label of "non-ideal theory". Liam Murphy's Moral Demands in Nonideal Theory addresses a moral question that arises when some agents do not comply with moral obligations. As such a world is less than ideal, Murphy describes his position as an exercise in non-ideal theory. The problem he is concerned with is that there is something unfair about beneficence under such conditions: when some do not do their bit to help those in need, the virtuous must do

\footnotetext{
${ }^{5}$ For representative examples, see: Holly Lawford-Smith, "Non-Ideal Accessibility", Ethical Theory and Moral Practice 16, no.3 (2013): 653-669; Colin Farrelly, "Justice in Ideal Theory: A Refutation", Political Studies 55 (2007): 844-864; Galston, "Realism in Political Theory", European Journal of Political Theory 9, no.4 (2010): 385-411.

${ }^{6}$ I have attempted to contribute to them myself: see my "The Circumstances of Justice", Hume Studies 36 no.2 (2010): 125-148.

${ }^{7}$ I find it striking, for example, how Valentini brackets discussion of 'the value of theorizing as such' from her paper: "On the Apparent Paradox", 341. For an important exception to my complaint, see Mills, "Ideal Theory as Ideology".
} 
even more. Suppose (though I do not agree) this is a problem. ${ }^{8}$ Murphy's solution is to insist that each is only obligated to do as much as would be required if everyone fully discharged their obligations of beneficence. ${ }^{9}$ Yet this solution involves a thoroughly idealized way of thinking.

Consider what is intrinsic to ethical reflection as Murphy understands it. It is intrinsic to Murphy's reflection that moral standards involve a metric for calculating the amount of good one must do. To answer the question "How much does beneficence require of $m e$ ?", Murphy would have the reflective subject calculate what would be required to bring about the state of affairs in which the global demands of beneficence are satisfied, and then divide this sum fairly among all natural and artificial agents, to determine their own fair share. Murphy acknowledges that a precise calculation is probably beyond us. But as long as individuals make 'good-faith' attempts at the calculating the equation, using 'rough guesses' supplemented by 'informed estimates of experts', the principle is sound as a 'background standard against which agents assess their standing motivations and rules of thumb. ${ }^{10}$ I am not so sure. It strikes me that Murphy must make significant idealizations about reflection itself before his calculation is even intelligible.

One cannot ask "How much does beneficence require me to do?" as if beneficence's metric could be calculated in isolation from other moral considerations. If I am not acting well, I am not acting beneficently, and so to think about what it is to act beneficently I must think about what it is to act well generally. ${ }^{11}$ Furthermore, the

\footnotetext{
${ }^{8}$ I cannot understand how an agent who is just, fair, beneficent, kind, etc. would consider taking up the slack of others' wrongdoing to be unfair. To think so would be to view one's moral obligations as onerous burdens rather than necessary elements of living well. That necessity strikes me as a central part of how the moral agent's grasp of ethical concepts silences certain considerations as reasons for action. The moral agent may, in severe cases, regret what living well costs them, but that is not the same as considering their obligations to be unfairly onerous. I take the notion of silencing from John McDowell, "Virtue and Reason", reprinted in his Mind, Value, and Reality (Cambridge MA: Harvard University Press, 1998), ch.3, at 55-56.

${ }^{9}$ Murphy, Moral Demands in Nonideal Theory, (New York: Oxford University Press, 2000), ch.5.

${ }^{10}$ Murphy, Moral Demands in Nonideal Theory, 118-120.

${ }^{11}$ Both Onora O'Neill and John McDowell have persuasively noted the ways in which one's wider ethical outlook is implicated in any individual practical judgment:
} 
claims of need and assistance that the beneficent agent responds to typically have incredibly complex causes in which an array of injustices are implicated. ${ }^{12}$ Many quotidian areas of moral life will be shaped in subtle ways by the effects of such injustice: the personal is after all the political. This adds considerable complexity to what is involved in acting well.

With these points in view, Murphy's conception of beneficence would have to involve a calculation of how much one needs to do to act well generally. Here, the idealized nature of Murphy's thinking is revealed. A calculation of how much one needs to do to act well generally could only make sense if the limits to the set of possibilities for acting well could be given. Murphy's thinking must presuppose a standpoint from which these limits are known: he admits we are not good at making the calculation, but insists it is in principle possible. But as human powers of cognition and reflection are finite, the possibilities for human interaction - and thus the possibilities for acting well - must be understood to be indefinite. ${ }^{13}$ The limits of the set of possibilities for acting well are impossible to cognize, and it is only when one idealizes away our finite capacities for reflection that Murphy's moral mathematics becomes something that could intelligibly apply to human interaction. If this is right, we cannot know what Murphy's proposed principle of beneficence could mean. The reflective standpoint Murphy presupposes is not one a reflective subject could take up, and so is no reflective standpoint at all.

My aim here is only to use Murphy's position to illustrate the point that even if a certain feature of the world, such as non-compliance, is not idealized away, one's

O'Neill, "Normativity and Practical Judgement", Journal of Moral Philosophy 4, no.3 (2007): 393-405 at 402-403; McDowell, "Virtue and Reason", 65-69.

${ }^{12}$ I have tried to draw attention to the significance of this point elsewhere, in my "Kantian Imperfect Duties and Modern Debates Over Human Rights" Journal of Political Philosophy 22, no.4 (2014): 396-415; and "Subsistence Needs, Human Rights, and Imperfect Duties", Journal of Applied Philosophy 30, no.1 (2013): 88100.

${ }^{13}$ One might think this claim needs qualifying: the bounded scope of possibility is beyond our ability to cognize, but matters would be different for God or an ideal observer. I suspect such a qualification is meaningless, because neither alternative is an alternative for us. See, for careful argument on the general point, Jonathan Lear, "Transcendental Anthropology", in his Open Minded (Cambridge MA: Harvard University Press, 1999), ch.11. 
theorizing about how to account for that feature may be thoroughly idealized. A defender of Murphy's position would no doubt wish to contest the objection I have briefly raised against it. Such a debate would be about whether the idealization Murphy makes use of is justifiable. If we limit philosophical scrutiny of idealization to features of the world to which the conclusions of theory are to be applied, that debate cannot even register. That would be unfortunate.

\subsection{The form of reflection is of central importance}

I now turn to a second reason for expanding the scope of the debates over idealization and ideal theory to include the form of reflection itself. Philosophical thought is, after all, inherently reflexive: to reflect philosophically about something is at the same time to reflect on the nature of philosophical reflection itself. Because assumptions about the form of reflection color answers to the question of which other features of the world can be justifiably idealized away, it is essential to give philosophical scrutiny to the form of reflection itself.

Again, it may be helpful to illustrate the point with an example. Consider Onora O'Neill's claim that practical reason is necessarily abstract, but cannot support idealization. ${ }^{14}$ Idealization, as noted earlier, falsifies some feature of the world. By contrast, abstraction does not deny the existence of predicates, but brackets them: ' $[\mathrm{r}]$ easoning that abstracts from a predicate makes claims that do not depend on that predicate holding, or on its not holding. ${ }^{15}$ O'Neill's is a clear conceptual distinction. A statement that brackets some feature of the world is not the same as a statement that falsifies that feature of the world.

\footnotetext{
${ }^{14}$ O'Neill, Towards Justice and Virtue, 39-41.

${ }^{15} \mathrm{O}$ 'Neill, Towards Justice and Virtue, 40. I have found in conversation at several conferences that this clear distinction is widely misunderstood, and the source of that misunderstanding seems to be Henry Shue's famous paper "Torture in Dreamland", Case Western Reserve Journal of International Law 37 (2006): 231-239. Shue, acknowledging O'Neill, claims that idealization adds something positive to an example while abstraction deletes something negative. (See Shue, 231 and fn4). Not only is this a misreading of O'Neill, it is also nonsensical. If I stipulate a world without slavery, have I added a positive (more freedom) or deleted a negative (less domination)? If the answer must be one or the other, there is no answer.
} 
Nevertheless, Alan Hamlin and Zofia Stemplowska have recently found O'Neill's distinction 'murky in practice', while Holly Lawford-Smith declares it 'flimsy at best'. ${ }^{16}$ The problem they find is this: if an idealized model of justice/right action does not deliver false results, there is no straightforward sense in which the idealization problematically falsifies. ${ }^{17}$ As Lawford-Smith claims, 'it doesn't matter if the [theory's] assumptions are literally false'. As long as such idealizations remove barriers to truth, and allow for the possibility of reintroducing real-world complexity at some later point of deliberation, the theoretical model can deliver conclusions that are truly normative. ${ }^{18}$

This claim that falsification is unproblematic strikes me as the standard defense of idealization in modern moral and political philosophy. Reflection on justice, or any other ethical concept, is understood as aspiring to accurately capture what that concept $i s$, by way of a theoretical model of right action (and, in the case of social justice, of the institutional structures that mediate right action). It is then argued that theoretical modeling of justice and other values can make use of simplifying idealizations to better illuminate what those values are, so idealization is not problematic if the theoretical model does not deliver false results. Thus Stemplowska, in an important related paper, insists that unless simplifying idealizations are employed, reflection on justice will not be able to get a grip on its object: 'the complexity of the problem will be simply too great. ${ }^{, 19}$

Yet note how both Lawford-Smith and Stemplowska take for granted a focus on results delivered by a theoretical model of what justice requires. I find it striking that both explicitly appeal to the use of idealization in scientific theorizing to vindicate

\footnotetext{
${ }^{16}$ Stemplowska and Hamlin, "Theory, Ideal Theory, and the Theory of Ideals", 50; Holly Lawford-Smith, "Ideal Theory: A Reply to Valentini", Journal of Political Philosophy 18, no.3 (2010): 357-368 at 366.

${ }^{17}$ Stemplowska and Hamlin, "Theory, Ideal Theory, and the Theory of Ideals" Political Studies Review 10, no.1 (2012): 48-62 at 50-51; Lawford-Smith, "Reply to Valentini", 363-366. Lawford-Smith actually foregrounds a different reason for the flimsiness of O'Neill's distinction: 'we can redescribe bracketing as asserting the absence of predicates'. (366). As this is contradicted by O'Neill's own remarks on bracketing I quoted above, I discard it accordingly.

${ }^{18}$ Lawford-Smith, "Reply to Valentini", 366.

${ }^{19}$ Stemplowska, "What's Ideal About Ideal Theory?", Social Theory and Practice 34, no.3 (2008): 319-340, at 327.
} 
points about idealization in philosophical theorizing about justice. ${ }^{20}$ Neither critic places significance on the fact that O'Neill's is a claim about practical reason. Instead, Lawford-Smith and Stemplowska assume that the same form of reflection is appropriate to scientific theorizing and to reflection on how we should live. If this assumption is accepted, practical reason can be nothing more than reasoning on the topic of practice. I think it is only in light of this assumption that Stemplowska and other defenders of idealization can offer the defense that idealization aids clarity. Moral and political theories should, just as scientific theories do, employ idealizations to screen out (what my scientist friends typically refer to as) the distracting and irrelevant noise arising from the complexity of the real world.

My impression is that this assumption about the shared form of scientific and normative theorizing is widely held in modern moral and political philosophy. ${ }^{21}$ It may (I am honestly unsure) be the orthodox view. But I am sure it was not always the orthodox view. And so it can be challenged by the ancient distinction, sustained in Aristotelian and Kantian thought, between the forms of practical and theoretical reason. But, again, this challenge cannot even register unless we expand the scope of debates around idealization and ideal theory to include the form of reflection itself.

\section{The form of practical reason}

The distinctive form of practical reason, and the distinctive form of knowledge it involves, has many aspects, and may be considered under only some of them. For example, it is possible to consider the nature of reflection on what one is doing largely in abstraction from reflection on what should be done, without denying that these are fundamentally interconnected aspects of practical reason. ${ }^{22}$ Here, my focus will be on judgment about what should be done. In order to make clear the distinction between

\footnotetext{
${ }^{20}$ Lawford-Smith, "Reply to Valentini", 365; Stemplowska, "What's Ideal About Ideal Theory?", 323. Compare also Valentini, "On the Apparent Paradox", 354; Estlund, "Utopophobia", 134.

${ }^{21}$ As Maike Albertzart notes in an acute discussion, many accounts of moral realism explicitly draw analogies to scientific reasoning, and many accounts of moral principles explicitly portray principles as akin to theoretical laws: Moral Principles (London: Bloomsbury, 2014), 94-95.

${ }^{22}$ Following Stephen Engstrom, The Form of Practical Knowledge, (Cambridge MA: Harvard University Press, 2009), 54-55. Engstrom's book is an exemplary discussion of the latter qestion; Anscombe's Intention of the former.
} 
the forms of practical and theoretical reason, it may again be useful to consider an example. To my knowledge, Elizabeth Anscombe provides the best.

\subsection{Practical reason is such as to produce its object}

A man is putting items into a basket in accordance with a shopping list, while a detective is following the man about recording what he is placing into the basket. Anscombe draws our attention to a difference between the two:

[I]f the list and the things that the man actually buys do not agree, and if this and this alone constitutes a mistake, then the mistake is not in the list but in the man's performance (if his wife were to say: 'Look, it says butter and you have bought margarine', he would hardly reply: 'What a mistake! We must put that right' and alter the word on the list to 'margarine'); whereas if the detective's record and what the man actually buys do not agree, then the mistake is in the record. ${ }^{23}$

This example is not, contrary to some interpretations, meant to illustrate the distinction between the mental states of desire and belief. It illustrates a distinction between two forms of reason.

If the detective's record does not match what the shopper purchases, then the detective will have made a mistake because the detective's reasoning is such as to arrive at an accurate representation of how the world is. If the shopper's purchases do not match his shopping list, then he too will have made a mistake in virtue of the form of his reasoning. Yet the shopper's mistake would be of a very different sort, and in grasping this we start to grasp the distinction between two forms of reasoning. The shopper's mistake would lie 'in the man's performance', and this is because the shopper is engaged in an exercise of reason that guides the action of the reflective subject. Should he buy margarine instead of butter, the shopper's action will have failed to instantiate the standards deployed in his reasoning. So here we have a distinction between two forms of reasoning. Practical reasoning is not such as to represent what is independently the case. Practical reasoning, unlike theoretical reasoning, is such as to produce that which it is reasoning about.

${ }^{23}$ Anscombe, Intention (Cambridge MA: Harvard University Press, 2000), 56. 
The key to understanding the distinction between the forms of practical and theoretical reason lies in grasping the idea that practical reason is such as to produce its object. In the application of a concept to an object in an exercise of theoretical judgment, the object of the judgment is already given to the reflective subject independently of the movement of thought constituting the judgment. A reflective subject either subsumes a given particular under a given universal, or seeks the appropriate universal for a given particular. So, for example, observing someone shopping I might inquire "Was that butter she purchased?" or (if, say, I were a visiting anthropologist set down in an unfamiliar culture), "What is she doing?" In either sort of case, the exercise of theoretical reason is such as to determine what the object of the reasoning is, but obviously is not such as to be capable of producing the object of the reasoning.

In contrast, the object of a practical judgment is not independently given to the reflective subject. The object of a practical judgment is what should be done, and this is not a feature of the world that is already to hand. When, for example, a subject judges the bribe should be declined, the subject understands that it is through this very judgment that she is to decline the bribe. Her judgment is such as to produce what should be done. So here we have reasoning and knowledge that cannot be theoretical in form, for if the reasoning and knowledge is such as to produce its object, its object cannot be something given independently to the subject.

Thus far, my remarks may suggest that the object of practical reasoning is really the doing of what should be done, where what should be done is already to hand. The reader should banish any such notion from their mind! The object of a practical judgment is what should be done. The act instantiating that "what" cannot be already to hand, for it is something yet to be performed. So in deploying concepts in practical judgment, the reflective subject is not applying those concepts to a particular act that is given independently to the subject. A shopper, for example, will be deploying a complex constellation of standards. Perhaps she is aiming to get the week's shopping and also to get value for money and avoid supporting exploitative companies and not disappoint her wife and be home by 6pm and so on. Each standard by itself is not the object of the practical judgment. Rather, the object of the practical judgment is the unity of all these standards, and it is only through an exercise of practical judgment 
that the standards are unified. In this way, the object of practical judgment is what should be done. ${ }^{24}$

A practical judgment, then, is a specification of action through the unification of a plurality of standards the reflective subject identifies with (insofar as unity is possible - hard cases can of course exist). These standards are standards of reason. The subject's knowledge that this should be done is delivered by a practical judgment combining a plurality of reason-giving standards, and so the subject's knowledge that this should be done includes knowledge of the force of the reasons for doing this. ${ }^{25}$ In this way, practical judgment is such as to determine its object. I use the locution "...is such as to..." to signal that is always possible the subject will not do what should be done. A subject who judges the bribe should be declined may still take the bribe through weakness of will, just as Anscombe's shopper might absentmindedly buy margarine. This possibility represents a mistake in virtue of the very form of the subject's reasoning.

Because the object of theoretical reason is given independently to the subject, whereas practical reason is such as to produce its object, these are two clearly distinct forms of reason. Yet it is easy to think that the distinction is in fact blurred. One might, for example, point to reasoning characteristic of medical practice. Medical science is clearly theoretical, and yet (one might say) is such as to produce good health, which is

\footnotetext{
${ }^{24}$ The preceding two paragraphs are heavily indebted to O’Neill, "Modern Moral Philosophy and the Problem of Relevant Descriptions", in Anthony O'Hear (ed.), Modern Moral Philosophy (Cambridge: Cambridge University Press, 2004): 301-316, at 311-313, and Stephen Engstrom, "Constructivism and Practical Knowledge", in Carla Bagnoli (ed.) Constructivism in Ethics (Cambridge: Cambridge University Press, 2013):133-152, at 144-146.

${ }^{25}$ This is perhaps the most controversial claim I make in this section: surely it is possible for a subject to judge the bribe should be declined and yet - non-akratically take the bribe anyway? I think we should deny that possibility and say, with McDowell, that non-defective knowledge of what to do must include knowledge why one should do it. See "Virtue and Reason" $\$ 3$. I can only gesture here to why we should think this. Crudely: the question of what to do is a practical question: its answer must provide action-guidance. And for a reflective creature, who can choose to do whatever they please, action-guidance must include a justificatory element: to understand what to do is to understand why one should do it.
} 
its object. ${ }^{26}$ So the distinction in form that seemed clear in the abstract now appears blurred in reality.

The apparent blurriness of the distinction in form between practical and theoretical reason dissipates once one grasps that the two forms of reason do not operate in isolation from one another. To continue with the example of medicine, it would be a mistake to characterize so complex a human undertaking as an instance of either theoretical or practical reasoning. The practice of medicine displays both forms of reasoning. There is an audible difference between the judgments "Does this cure cancer?" and "How should we respond to the presence of cancer in this patient?" In the former case, the object of the judgment is independent of the reflective subject, and so the reasoning cannot be such as to produce its object. In the latter case, the object of the judgment is what should be done, understood as the unity (insofar as possible) in action of a complex constellation of standards. The surgeon should, for example, act both ethically and effectively. And in understanding this is what should be done, the surgeon understands she is to act accordingly.

A surgeon's practical judgment "How should we respond to the presence of cancer?" will of course make use of the deliverances of theoretical judgments about, for example, effective treatment, just as Anscombe's shopper needs to know where the supermarket is. If an agent is to successfully instantiate in her action the standards that guide it, she needs to know a good deal about how the world relevantly is. But these pieces of theoretical knowledge are not the objects of practical judgments, and so the distinction in form is not blurred. Nor do these pieces of theoretical knowledge feature in practical judgments in quite the same way as they do in theoretical judgments. For example, a theoretical judgment that a patient has a bad reaction to anesthetic would simply identify the relevant fact. In the practical judgment "How should we respond to the presence of cancer in this patient?", by contrast, such a fact is relevant because it is an obstacle. Practical reasoning involves an understanding of the relevant features of how the world is precisely because those features are relevant to shaping action that instantiates the standards deployed in that reasoning. ${ }^{27}$

\footnotetext{
${ }^{26}$ Many thanks to the anonymous $S P P$ reviewer for this helpful example.

${ }^{27}$ On this point I am indebted to Anton Ford, "On What is in Front of Your Nose", Philosophical Topics, forthcoming 2016; and Anselm Müller, "How Theoretical is
} 
With the distinction in form between practical and theoretical reason clarified, I would like to signal one implication of it. That the form of practical reason is such as to produce its object entails that practical reasoning is an exercise of the productive faculty, the will. Any exercise of the will must be constrained by the conditions of its own productive possibility: it could not otherwise be productive, and so mere wishful thinking is not an exercise of the will. ${ }^{28}$ So it must also be intrinsic to practical judgment that it acknowledges the conditions of the will's productive possibility. In $\S 3$, I attach considerable significance to this point.

\subsection{The scope of practical reason}

The assumption noted in $\S 1.2$, that reflection on standards of justice and morality is fundamentally theoretical, may seem untroubled by the distinction in form I have just drawn attention to. A familiar line of thought holds that reflection on the nature and justification of the standards one deploys in practical reason is outside the scope of practical reason: reflection on the nature and justification of those standards is an exercise of theoretical reason. $^{29}$

Further reflection on the standards of practical reason can, however, undermine this familiar view of practical reason's scope. Standards of practical reason admit of different types. Following Sebastian Rödl, ${ }^{30}$ some ends are finite, insofar as an action instantiating that end brings about the completion of that end: for example, the typing of this sentence. Other ends are by contrast infinite, insofar as an action instantiating that end manifests one of an indefinite number of possibilities for exemplifying the

Practical Reason?", in C. Diamond and J. Teichman (ed.) Intention and Intentionality, (Cornell: Cornell University Press, 1980), 91-107. In earlier work I tried to register the point by saying that practical reason's direction of fit does not run entirely one way ("The Circumstances of Justice", 140). I now regret the phrasing (it blurs the distinction in form), though not the point.

${ }^{28}$ Kant, Groundwork to the Metaphysics of Morals (trans. J. Timmermann, Cambridge: Cambridge University Press, 2011), 4:394.

${ }^{29}$ Two prominent examples: John Broome, Rationality Through Reasoning (Oxford:

Wiley, 2013), 23-24; and David Velleman, The Possibility of Practical Reason (Oxford: Oxford University Press, 2000), ch.10.

${ }^{30}$ Sebastian Rödl, "The Form of the Will”, in Sergio Tenenbaum (ed.), Desire, Practical Reason, and the Good (Oxford: Oxford University Press, 2010): 136-160, at 146-149. 
particular way of acting prescribed by that end. Think, for example, of acting justly or dressing stylishly or keeping fit. Having typed this sentence, I can in future only type other sentences; having acted justly, I can at any point in my future act justly again. Infinite ends do not come to a limit in any individuated temporally finite actions. Rödl's distinction helpfully marks out how some standards of practical reason possess much greater generality than do others. But as the label "infinite" has the potential to distract from this point, I shall refer to such standards as general standards.

Within the class of general standards, a further distinction can be drawn. Some general standards are extremely unremarkable: consider typing in English. Other general standards are more interesting, in that they are instantiated in the shape of one's life. This point unfortunately requires more yet more jargon. Reflection on what I should do, in the sense of a temporally finite action, can at the same time be reflection on what I should do in the broader sense of my on-going activity. By "activity" I mean a way of going on that is continuous - temporally finite only insofar as it might be stopped (by e.g. incapacity or rejection), not that it comes to completion - and that is determined by the active subject's reflection. So, for example, the lifecycle of a mayfly, although continuous, would not be an instance of activity in my jargon. A human living a meaningful life, by contrast, would be the broadest possible example of an activity. ${ }^{31}$

The general standards instantiated in the shape of one's life provide action-guidance in a complex way. General standards provide guidance with respect to individuated, temporally finite actions, where practical judgment shapes the action to be done in light of the various standards to be instantiated in that action. General standards also guide activity, embodying the central ordering concepts that both constitute an agent's understanding of what is worthwhile, and serve to connect and cohere the various standards that are particular to the various domains, roles, or facets of an agent's life.

\footnotetext{
${ }^{31}$ My jargon here owes a lot to Aristotle's distinction between energeia and kinêsis, at Metaphysics 1046b, and especially to Charles Hagen's interpretation in "The Energeia/Kinêsis distinction and Aristotle's Theory of Action", Journal of the History of Philosophy 22, no.3 (1984): 263-280. Compare Rödl, "The Form of the Will”, 146147.
} 
A practical reasoner must possess some general orienting standards. It is certainly possible to imagine someone who could reason about quotidian tasks (e.g. cooking), but who had lost the central ordering concepts that make their overarching activity intelligible. Such a fate has befallen many colonized peoples for periods of their history. ${ }^{32}$ Yet such a person would be capable of practical reasoning only to a severely attenuated degree. Having lost the central ordering concepts that make their activity intelligible, such a person could only understand quotidian tasks as prolonging life, but not what life amounted to and so why it should be prolonged. If that is correct, it is intrinsic to (non-defective) practical reasoning that the reflective subject possesses general orienting standards.

Finally, the standards that orient activity are subjective, in the peculiarly Kantian sense of belonging to the reflective subject. They are standards I myself, the subject, have made my own by adopting them as maxims, and in doing so committing myself to applying the standards, when appropriate, in practical judgment. ${ }^{33}$ Or synonymously - it is to adopt the reason-giving concept (justice, kindness, honesty, etc.) embedded in the standard as a central ordering concept that orients my activity: a concept I am to live by. ${ }^{34}$ I cannot reasonably do this unless I take the standards I am adopting as maxims to pass a test of reflective scrutiny, and so deliberation about which general standards should orient my activity just is the task of determining which standards are philosophically justified.

To accept the justification for some standard is to adopt the relevant principle as a maxim that orients my activity. In making a standard my own, the deployment of that concept with respect to my activity is such as to produce the activity in question (in judging I should live justly, I understand it is through this judgment that I am to be just). And so it appears - doesn't it? - that reflection on the nature and justification of the standards of practical reason is itself an exercise of practical reasoning: an exercise of a thoroughly reflexive aspect of practical reason, but which, for all that, is still reasoning about what one should do and is doing.

${ }^{32}$ This possibility is brilliantly examined by Jonathan Lear, Radical Hope (Cambridge MA: Harvard University Press, 2008), see especially 56-62.

${ }^{33}$ Compare O'Neill, Towards Justice and Virtue, 164.

${ }^{34}$ Following Adrian Moore, "Maxims and Thick Ethical Concepts", Ratio, 19, no.2 (2006): 129-147; at 135-138. 


\section{Standards of justice and morality are standards of practical reason}

I have attempted to motivate the view that practical reason is distinct in form from theoretical reason, and that the standards of practical reason are not given to it through exercises of theoretical reason. This raises the question of whether proponents of idealization are entitled to the assumption that reflection on standards of justice and morality is theoretical in form. I am now in a position to argue that we should reject this assumption.

\subsection{Against the priority of theoretical reason}

One ground for holding that reflection on the nature and justification of standards of justice and morality is an exercise of theoretical reason, is to suppose that a (theoretical) account of what those standards are must be in place before any (practical) account of how we should act is given. In modern political philosophy, perhaps the most famous assertion of this claim is Gerry Cohen's. Cohen, if I understand him, insists that we must first inquire into what the correct principles of justice are before we can consider the question of how justice should guide action. Cohen writes:

It is not the purpose of fundamental principles to guide practice, any more than it is the purpose of arithmetic to reach by calculation truths about the empirical world [...] that purpose is not constitutive of what arithmetic is: if the world were to become too chaotic for arithmetic to be applied to it, arithmetic would remain exactly what it now is. And fundamental principles indeed serve the purpose that (when combined with the facts) they tell us what to do, but their standing, too, lies upstream from their serving practical purposes. ${ }^{35}$

To borrow Cohen's own misappropriation of Justinian, the idea is that justice is each getting their due, which can be determined independently of any considerations of how - or even whether it is possible - each might get what they are due. ${ }^{36}$ This is to

\footnotetext{
${ }^{35}$ Cohen, Rescuing Justice and Equality, 266-267.

${ }^{36}$ See Cohen, Rescuing Justice and Equality, 252-3. What Justinian says is this: 'Justice is the set and constant purpose which gives to every man his due.' Institutes I.i (trans. J.B. Moyle, Oxford: Oxford University Press, 1913). I find it striking that Cohen, after initially accurately glossing the passage, immediately drops the emphasis on giving, and places emphasis on the recipients of justice.
} 
think of the concept of justice as, ultimately, denoting a state of affairs. This strikes me as a very popular thought: Stemplowska, for instance, asserts that normative theory must enable us 'to judge what we have already achieved against a final landmark of where we ought to be' ${ }^{37}$

Cohen elsewhere asserts the priority of theoretical reflection by saying that a reflective thinker might care about what justice is without caring at all about how standards of justice should guide practice. ${ }^{38}$ This has invited the skeptical response from David Miller, that it is hard to understand why anyone would care about what justice is if they did not care about how we should act or the structure of the social institutions through which we interact. ${ }^{39}$ I think a stronger variant of that skeptical response should be offered: it seems impossible to understand what justice is in isolation from understanding how standards of justice guide action.

Consider again Cohen's gloss of justice as what each is due. Perhaps this is a failure of imagination on my part, but I cannot understand what " $d u e$ " could mean if it does not signal that something must be done; a pattern of action produced. To say that something must be done is to identify a constraint, in the form of an obligation, on the exercise of the will of one or more agents. To think about what someone is due is to think about how others are required to act. It is to locate the possessor of the entitlement within a particular sort of practical nexus with one or more others: a nexus constituted by the obligations to which the entitlement is correlative. I say practical nexus because what is joined in this connection is the activity of the different agents in question. Accordingly, unless one can account for both the identities of obligationbearers and the content of their obligations, thought about entitlement is empty: such thought would be unable to locate the entitlement holder within any practical nexus of the correct sort. ${ }^{40}$

\footnotetext{
${ }^{37}$ Stemplowska, "What's Ideal About Ideal Theory?", 332.

${ }^{38}$ Cohen, Rescuing Justice and Equality, 306-7.

${ }^{39}$ Miller, Justice for Earthlings (Cambridge: Cambridge University Press, 2013), 232.

${ }^{40}$ Compare Michael Thompson, "What is it to Wrong Someone?", in R.J. Wallace, P. Pettit, S. Scheffler, and M. Smith (ed.) Reason and Value (Oxford, Clarendon, 2004), 333-384, and O'Neill, Towards Justice and Virtue, ch.5. To deny this would be to hold the view that there is an intelligible way of saying "She ought to have this and that" where the ought does not depict any practical nexus. Holly Lawford-Smith has asserted that this is intelligible: in the case of a loved one killed in a natural disaster,
} 
So there can be no account of what justice is isolated from an account of how agents ought to act. It is worth asking what would be needed for an account of the latter. It might be thought that all one needs is a sufficiently substantive specification of what ought to be done - which a theoretical model could provide. But if that is all that is required, the account will have left agency out of the picture altogether. Such an account would treat the doers of what ought to be done as functional components of a process, and in this respect they could be replaced by complexly-programmed robots with no difference made to the theory. To think of others in this way is not to think of them as acting at all. Acting involves the reflective exercise of the will. An account of how we should act must recognize that the enacting of what ought to be enacted involves exercises of the productive faculties of those who enact it. So any such account must provide a vindicatory explanation of how the standards of justice can be willed by those who are to enact them.

Going further, and connecting the point to $\S 2.2$ above, to will a principle is to make it one's own: it is to adopt the principle as a guide to action on the basis of that principle passing a test of reflective scrutiny. For reflective agents, who are free to adopt any standards they see fit, action-guidance cannot just be a matter of the standard's having sufficient content. No standard could be action-guiding for a reflective agent if unsupported by reasoning that vindicates the adoption of that standard. ${ }^{41}$

When considering a plurality of agents, the reasoning that justifies those standards must be able to coordinate the wills of all members of that manifold. I use "coordinate" in a specific and perhaps uncommon sense here. I am not thinking of the

'[w]e have a strong intuition there that life really ought not to be so unfair as to have let this be the case'. "Reply to Valentini", 359fn4.

I cannot make sense of Lawford-Smith's claim, other than as what she explicitly denies it is: an empty remnant of an enchanted worldview we have discarded. What Lawford-Smith describes is an exercise of purely wishful thinking. As such, it is entirely appropriate to grief and mourning, which are themselves entirely appropriate reactions to the death of a loved one. But that something ought to happen is a matter of the exercise of the will. Willing cannot be purely wishful thinking, and so purely wishful thinking cannot contain a genuine example of an ought. See above, §2.1. ${ }^{41}$ Valentini, "On the Apparent Paradox", 342 fn49, also separates the issue of justification from action-guidance, though I cannot see her reasoning for it. If what I have said and go on to say is correct, this must be a mistake on her part. 
way artifacts of game theory and the like may be used to model a pattern of behavior in solving "coordination problems". I am thinking of what it would take for a standard to survive the reflective scrutiny of a plurality of agents, such that each can adopt the standard as their own. To adopt a standard as one's own is, I've argued, an exercise of practical reasoning. So the test of reflective scrutiny must have the form of practical reason: it is reasoning about which central ordering concepts shape one's activity. (I will say a little below about the criteria reasoning must meet if it is to be capable of coordinating a plurality of wills).

Let me bring these points together. It is impossible to say what each is due without saying how others should act. It is impossible to say how others should act without saying what others should will. And it is impossible to say what others should will without saying how it is possible for reasoning to coordinate the wills of a plurality of agents. So reasoning about what justice is must be such as to produce its object: it is practical reasoning. The nature of justice is captured by a constellation of principles embodying standards that bind both the activity of agents, and the institutions through which that activity plays out, into a practical nexus of obligation. Criteria of justice are not derived from an ideal state of affairs.

Indeed, a proper grasp of what, in \$2.2, I called an infinite or general orienting standard cannot require any depiction of an ideal state of affairs. When we think of the indefinite scope of possibilities for human interaction, it appears that the reasongiving concepts of justice, compassion, honesty, benevolence, and so on (and all the negative ones: cruelty, neglect, deceit....) must have the form of general standards. To grasp such a general standard is to understand the orienting role that standard plays in the open-ended activity of life. Precisely because such activity is indefinite, a proper grasp of any such standard cannot involve the specification of a final landmark, an ideal state of affairs. To properly grasp such a standard is to grasp how a reflective subject could adopt it as something to be unfailingly observed in their open-ended activity of life. This is to grasp how justice operates as a standard of practical reason, not to grasp any final landmark depicted by an ideal state of affairs. ${ }^{42}$

\footnotetext{
${ }^{42}$ It has been put to me, by Sem de Maagt and by the anonymous reviewer, that this argument presupposes the falsity of certain forms of moral realism that defenders of idealization may hold. It would be very interesting to investigate to what extent
} 


\section{2: Against the use of idealization}

One could agree that justice and other moral standards are general standards, and that it is impossible to grasp the nature of these standards in isolation from considerations of practice, and still hold that idealization is essential to reflection on the nature and justification of such standards. For accepting that justice is a general standard, we must understand the complex nature of this standard, and its relation to other standards, and the broad structure of the ethical outlook in which this standard is located, if reflective scrutiny is to recommend justice as a central ordering concept. This thought returns us to the defense of idealization noted in $\S 1.2$ : on all these points, idealization is either essential or extremely useful.

Stemplowska provides most powerful version of this argument. We must consider how standards of morality and justice interconnect, and, Stemplowska claims, it is far easier to 'tease out the relationship between two principles' in the context of 'a radically simplified universe'. Further, 'by assuming the fanciful we can see more clearly how crucial certain constraints are to shaping what we consider desirable or just when they are present'. ${ }^{43}$ Thirdly, we must also take thought about what our standards demand of us, and idealization is essential to prevent 'existing constraints on what we can achieve' from distorting 'our understanding of what a given value requires' ${ }^{44}$ If these claims are accepted, idealization to eliminate distracting noise is equally appropriate in reflection on how we should live as it is in scientific reflection.

Yet once it is accepted that reflection on how we should live has the form of practical reason, the claim that idealization aids clarity must be abandoned. To see why, it is

defenders and critics of idealization rely on differing answers to the question of moral realism. My argument here is not, however, intended to presuppose the falsity of certain forms of moral realism, but to open up one way of rejecting the relevant forms. If my argument from general standards in $\$ 2.2$ is correct, then reflection on the nature and justification of general standards of practical reason must itself have the form of practical reason. And if it is then accepted that standards of justice and morality are general standards of practical reason, it may be possible to rule out varieties of moral realism that entail that reflection on the nature of normative concepts is theoretical. All this would need a lot more working out. But see also Engstrom, "Constructivism and Practical Knowledge".

${ }^{43}$ Stemplowska, "What's Ideal About Ideal Theory?", 327-328.

${ }^{44}$ Stemplowska, "What's Ideal About Ideal Theory?", 337. 
necessary to return to several conclusions that emerged in the course of explaining the form of practical reason. These are: that the object of practical reason is what should be done; that the distinct forms of reasoning are not isolated from each other; and that if practical reasoning is such as to produce its object it must acknowledge the conditions of the will's productive possibility.

The object of practical judgment is what should be done. This object is necessarily abstract, because there is always a gap between action and norm: any practical judgment can only shape the action to be done in such a way that leaves indeterminate the precise character of that action. ${ }^{45}$ A multitude of patterns of action may instantiate the standards involved in, for example, getting the week's shopping or respecting others' rights. Practical reason is also such as to produce its object, and the action, once done, is necessarily an entirely concrete historical event. So at the sharp end of practical reasoning, there must be a movement of thought from abstract standards to historically concrete action. ${ }^{46}$ Here, sanity requires a considerable number of assumptions, on the subject's part, about the state of the world. Flukes aside, that things are as one takes them to be is a condition of the will's productive possibility. It therefore belongs to the form of practical reason, considered under this aspect, that beyond a certain point the more assumptions one makes the more tenuous that reasoning becomes as a guide to action. Idealizations are impractical here: they constitute defective reasoning.

And this point - that idealizations are impractical - applies equally to the highly reflexive aspect of practical reasoning concerning the nature and justification of standards of justice and morality. Considered under this aspect, practical reason coordinates a plurality of wills. I must postpone until another occasion a full

\footnotetext{
${ }^{45}$ Compare O’Neill, "Normativity and Practical Judgement", 399-400. I think this is true even of certain negative injunctions that prescribe, as Kant puts it, with mathematical precision (Metaphysics of Morals [trans. M. Gregor, Cambridge: Cambridge University Press, 1996], 6:375fn). While there is an indeterminate number of ways of killing someone, the only way to meet a prohibition on murder is to never do any of them, as Jens Timmermann once pointed out to me. Yet there are still many possible patterns of action that all exhibit the complete absence of murder. ${ }^{46}$ On this see Ford, "On What is in Front of Your Nose", and O'Neill, "Normativity and Practical Judgement", 403. Compare Anscombe, Intention, 79: 'The mark of practical reason is that the thing wanted is at a distance from the immediate action'.
} 
discussion of what it would take for a principle to pass the reflective scrutiny of a plurality. But at least the following can be said. Reasoning that is such as to pass the reflective scrutiny of a plurality must be followable in thought by all it is addressed to. ${ }^{47}$ This claim involves a modality that is notoriously difficult to pin down. Yet it must also be true that whether a subject can reflectively identify with a particular reason-giving concept depends on which concepts that subject already reflectively identifies with. ${ }^{48}$ So this too can be said: reasoning that is followable in thought must establish connections that enable a movement of thought from the concepts one identifies with to the concepts that the reasoning promulgates identification with. (This movement of thought by no means must preserve the starting concepts unchanged). This must be a condition of the will's productive possibility.

The conditions for the productive possibility of a plurality of coordinated wills are accordingly complex. Human capacities for reflection and cognition are only actualized through habituation into a particular historically and culturally contingent intellectual inheritance. The concepts any particular individual identifies with are a matter of history and culture, with all the dizzying diversity that implies. They are also a matter of politics: think, for example, of the ways in which complex histories of injustice in a world disfigured by centuries of colonization charge certain concepts with political significance. ${ }^{49}$ Reasoning that is capable of coordinating a plurality of wills must account for the cultural and historical deposit embedded in the standards it promulgates. Such reasoning must also account for how that deposit stands in relation to the concepts held by the domain of subjects it is addressed to. If reasoning does not do this, it cannot show how the concepts it promulgates can connect to the concepts its audience identify with.

These historical and cultural contingencies are exactly what simplifying models of justice and right action typically idealize away. For example, theoretical models of the behavior and deliberation of an ideal community of agents, or of contracting parties, operate with a homogenous picture of the intuitions and motivations of agents in an

\footnotetext{
${ }^{47}$ O'Neill, Towards Justice and Virtue, 54ff.

${ }^{48}$ Moore, "Maxims and Thick Ethical Concepts", 146.

${ }^{49}$ See further Katrin Flikschuh, "The Idea of Philosophical Fieldwork", Journal of Political Philosophy 22, no.1 (2014): 1-26; and my own "Human Rights as One Thought Too Many? The Māori Case", Jurisprudence, forthcoming 2016.
} 
ahistorical context. The heterogeneity of cultural outlooks and thick ethical concepts, as well as the complex relevance of histories of injustice, is idealized away. Likewise, elaborately constructed thought experiments, typically involving fanciful scenarios, aspire to isolate and test moral intuitions in complete detachment from the constellation of historically and culturally contingent thick ethical concepts that would give the intuition content and reflective significance to any particular subject. None of what is being idealized away here is noise. These are essential materials for determining the conditions for the productive possibility of a coordinated plurality of wills. Far from aiding clarity, simplifying idealizations of the sorts just described make reflection on the nature and justification of standards of justice and morality reflection that is practical in form - impossible.

This objection also shows what is fundamentally wrong with the claim that idealization is unproblematic so long as real-world complexity is re-introduced at some later stage of reflection. To think this is to understand reflection on standards of morality and justice as a process of several steps. The most fundamental step is the identification of first principles or considered intuitions, and it is here that idealizations to screen out complexity are deemed, for reasons of the sort given by Stemplowska, either essential or extremely helpful. Having reached a philosophically clear and rigorous account of these standards, subsequent reflection can reintroduce idealized-away features of the world in order to determine what these standards require of $u s$ in the here-and-now. ${ }^{50}$

Practical reasoning typically exhibits a process that at first glance may seem identical to the multi-stage process just described. This is most obviously the case in reasoning about what one is doing, which - as noted - must involve a movement of thought from abstract standards to the performance of a particular historical event. But it is also the case in more reflexive practical reasoning about what should be done. O'Neill captures the point well:

The task of judging what is just begins with fixing principles of justice. Judging what it would be just to do is not a matter of discerning that particular acts meet (or would meet) those inclusive and very abstract

\footnotetext{
${ }^{50}$ The most famous example must be Rawls's 'four-stage process' for thinning the Veil of Ignorance: A Theory of Justice (rev. ed.) 171-176.
} 
principles. It is a matter of identifying more restricted principles and ways of living that fall within the constraints of justice [...] These less abstract, and often more restricted principles in turn provide a framework for the construction of institutions and practices that can be judged just in a given time or place..$^{51}$

Note, however, that with respect to both dimensions of practical thought, this is a process of the increasing concretization of initially highly abstract standards. It is not a process of re-introducing real-world complexity after making simplifying idealizations to arrive at clear first principles or bedrock intuitions.

Indeed, reflection on the nature of justice and other ethical standards cannot be a process of first employing idealizations to clarify first principles and then subsequently re-introducing what has been idealized away. Standards of practical reason must be capable of coordinating a plurality of wills, and this makes the idealization of real-world complexity impractical at the first, fundamental step of reflection. To repeat the three examples given above, the depth of cultural diversity, the complex relevance of historic injustice, and the historical, cultural, and political deposits contained within the reason-giving concepts one is reflecting upon, all fundamentally bear on the question of whether some proposed practical standard could pass the reflective scrutiny of a plurality of agents. For this reason, none of these considerations can be idealized away, only to be reintroduced at some later stage. The identification of first principles must be the identification of principles/reason-giving concepts that can coordinate a plurality of wills. Here, again, idealization is impractical. Stemplowska's claim that without simplifying idealizations the complexity is too great should be turned on its head. Without an accurate understanding of how complexities of culture and history feature in human reason, reflection on standards of morality and justice will be unable to get a grip on its object. $^{52}$

\footnotetext{
${ }^{51}$ O’Neill, Towards Justice and Virtue, 182.

52 This is to reach, via a different route, one of Bernard Williams's famous conclusions: that one defect of theory is that it 'represents as many reasons as possible as applications of other reasons [...] Our problem now is actually that we have not too many but too few' reason-giving concepts. Ethics and the Limits of Philosophy (London: Fontana, 1985), 116-117.
} 


\section{Concluding Remark}

Almost everything remains to be said, but I hope my main points are now clear. First, I hope I have shown the importance of expanding the scope of the debates about idealization in modern moral and political philosophy, to encompass the form of reflection itself. Second, I hope I have adduced some grounds for concluding that reflection on the nature and justification of standards of justice and morality takes the form of practical rather than theoretical reason. That conclusion should ultimately lead us to discard several orthodox aspects of modern moral and political philosophy, such as the use of simplifying idealizations.

In closing, I would like to stress again that nothing I have said supposes that theoretical reasoning is irrelevant to practical reflection. While idealized modeling of just/right action wrongly dismisses as distracting noise materials needed for an account of how reasoning can coordinate a plurality of wills, the theoretical disciplines of history, anthropology, and the history of ideas represent the best sources of those very materials. And it is because reflection on morality and justice is practical in form that the deliverances of these theoretical disciplines matter to it. 